\title{
State-Based Medicaid Costs for Pediatric Asthma Emergency Department Visits
}

William S. Pearson, PhD, MHA; Scott A. Goates, PhD; Samantha D. Harrykissoon, JD, MPH; Scott A. Miller, MPA

Suggested citation for this article: Pearson WS, Goates SA, Harrykissoon SD, Miller SA. State-Based Medicaid Costs for Pediatric Asthma Emergency Department Visits. Prev Chronic Dis 2014;11:140139. DOI:

http://dx.doi.org/10.5888/pcd11.140139 圈.

PEER REVIEWED

\section{Abstract}

\section{Introduction}

The prevalence of childhood asthma in the United States increased from 8.7\% in 2001 to 9.5\% in 2011. This increased prevalence adds to the costs incurred by state Medicaid programs. We provide state-based cost estimates of pediatric asthma emergency department (ED) visits and highlight an opportunity for states to reduce these costs through a recently changed Centers for Medicare and Medicaid Services (CMS) regulation.

\section{Methods}

We used a cross-sectional design across multiple data sets to produce state-based cost estimates for asthma-related ED visits among children younger than 18, where Medicaid/CHIP (Children's Health Insurance Program) was the primary payer.

\section{Results}

There were approximately 629,000 ED visits for pediatric asthma for Medicaid/CHIP enrollees, which cost $\$ 272$ million in 2010. The average cost per visit was \$433. Costs ranged from \$282,000 in Alaska to more than $\$ 25$ million in California.

\section{Conclusions}

Costs to states for pediatric asthma ED visits vary widely. Effective January 1, 2014, the CMS rule expanded which type of providers can be reimbursed for providing preventive services to Medicaid/CHIP beneficiaries. This rule change, in combination with existing flexibility for states to define practice setting, allows state Medicaid programs to reimburse for asthma interventions that use nontraditional providers (such as community health workers or certified asthma educators) in a nonclinical setting, as long as the service was initially recommended by a physician or other licensed practitioner. The rule change may help states reduce Medicaid costs of asthma treatment and the severity of pediatric asthma.

\section{Introduction}

Asthma is a chronic respiratory disease characterized by reversible periodic airway obstructions initiated by certain exposures, including environmental hazards (1). The disease is becoming increasingly prevalent in the United States, particularly among children and certain minority groups. More than 25 million people are currently diagnosed with the disease, including 6.5 million children younger than 18 (2). Although no cure for asthma is available, symptoms can be controlled with appropriate medical treatment, self-management, and education, and by avoiding exposure to environmental allergens and irritants that can trigger an attack (1).

Asthma in the United States costs $\$ 56$ billion annually for direct health care expenditures and indirect costs such as lost productivity (3). In 2009, asthma resulted in approximately 480,000 hospitalizations, 1.9 million emergency department (ED) visits, and nearly 9 million doctors' office visits (4). As the third leading cause of hospitalization among children younger than 15, asthma is associated with increased ED visits (5). Additionally, studies have reported 
a higher rate of health care use among children insured by Medicaid compared with children insured by other health insurance programs (6).

Despite increased attention on asthma prevention and advances in diagnosis and treatment, childhood asthma prevalence in the United States has increased from 8.7\% in 2001 to $9.5 \%$ in 2011 (7). Having a clinical care system that focuses on improving asthma management before cases become acute is essential. However, given the complexity of the disease, a comprehensive, community-based approach to educate and assist children with asthma outside of traditional clinical settings may be beneficial.

Asthma education programs provided in nontraditional settings, for example, in homes, can reinforce selfmanagement education and treatment by reaching children and parents where they live. These evaluated programs follow the National Asthma Education and Prevention Program evidence-based guidelines (1) that emphasize the need for asthma education at all points of care. Some studies have demonstrated that asthma home visitation programs may improve asthma management, reduce the number of missed school and work days, decrease allergens in the home, reduce urgent care use, and lessen caregiver stress $(8,9)$. Furthermore, in its systematic review of research, the Community Preventive Services Task Force found that home-based interventions with an environmental focus improve the overall quality of life and productivity in children with asthma (10).

Despite the significant burden of pediatric asthma ED visits, we were unable to find comprehensive estimates of Medicaid and Children's Health Insurance Program (CHIP) costs at the state level. We analyzed the cost of pediatric asthma ED visits, which are primarily paid for by Medicaid or CHIP at a state level. We then highlighted an opportunity for states to reduce asthma costs borne by their Medicaid programs because of a recent change to a Centers for Medicare and Medicaid Services (CMS) regulation. The rule change allows Medicaid to reimburse nontraditional health care providers for providing asthma prevention services in nontraditional settings.

\section{Methods}

Because data on pediatric asthma ED visits were not available for all states, we constructed a "second-best" approximation by using multiple sources of data that may not have included data from the same years. We chose the most recent data from each source to derive an estimate for a single year. We initially estimated the number of ED visits made by children aged o to 17 years where asthma was listed as one of the reasons for the visit and Medicaid or CHIP was the primary payer for the visit. For this part of the analysis, we used data from the National Hospital Ambulatory Medical Care Survey Emergency Department (NHAMCS-ED) survey.

The NHAMCS-ED is a national survey that collects information on the delivery and use of emergency care services at noninstitutional, general, and short-stay hospitals, excluding federal government facilities such as Veteran's Administration hospitals and military hospitals in the states and the District of Columbia. This multistage design survey collects data on randomly selected patient records during a 4-week sampling period (11).

To analyze all ED visits for asthma by children younger than 18, we searched hospital records for International Classification of Diseases, 9th revision (ICD-9) codes to estimate the total visits in 2010. Each visit record contained up to 3 ICD-9 codes that contributed to the reason for the visit. We searched for the asthma code of 493.xx and its subcategories (493-493.92) among these 3 ICD-9 diagnosis codes. We further limited our search to visits for which Medicaid or CHIP was the primary payer. We considered all ED visits with any diagnosis of asthma, regardless of whether the patient was discharged home or admitted to the hospital.

State-by-state asthma prevalence data were obtained from the National Survey of Children's Health (NSCH), 2012. This survey was sponsored by the Maternal and Child Health Bureau; the National Center for Health Statistics (NCHS) of the Centers for Disease Control and Prevention (CDC) oversaw the sampling. Data were collected by using the State and Local Area Integrated Telephone Survey (developed by NCHS) to randomly sample families from all 50 states and the District of Columbia. A total of 95,677 surveys were completed nationally for children aged o to 17 years, and a minimum of 1,800 surveys were collected for each state (12).

We used CMS enrollment data to determine the total number of children enrolled in state Medicaid/CHIP programs for each state. We obtained state-by-state enrollment data for children enrolled in Medicaid and CHIP in 2010 from the Kaiser Family Foundation website. The data provided in this report were available only for children aged o to 18 (13). We multiplied state enrollment data by the prevalence data for each state to estimate the total number of children with asthma covered by Medicaid or CHIP. This data source did contain enrollment data on children aged 18, which is 1 year older than the age range of o to 17 years for all other data sources used in these analyses. We were not able to adjust this number.

State estimates for the number of asthma ED visits for children younger than 18 were estimated by taking the total number of ED visits nationally (estimated by the NHAMCS-ED) and apportioning the visits to the states based on estimates of the number of Medicaid/CHIP enrollees with asthma in the state. For example, if a state covered 100,000 
children under Medicaid/CHIP and had an asthma prevalence rate of $7 \%$, we estimated that approximately 7,000 $(100,000 \times 7 \%)$ children with asthma were covered by Medicaid/CHIP in that state. If these 7,00o children represented $5 \%$ of all children with asthma covered nationally by Medicaid/CHIP, then we assumed that this state had $5 \%$ of all childhood asthma ED visits nationally.

We used Marketscan data to estimate the cost for pediatric asthma ED visits and subsequent hospitalizations. Costs for ED asthma visits and hospitalizations were obtained from the Marketscan Medicaid 2011 data set (the most recent year available). The Marketscan data set contains a convenience sample of claims data for Medicaid participants of 11 unnamed states (14). We estimated costs by identifying children younger than 18 who were treated in the ED with asthma as either the primary diagnosis or 1 of 3 secondary diagnoses. Cost estimates were limited to cases where Medicaid was the expected payer, and the patient was enrolled in a noncapitated plan.

\section{Results}

According to NHAMCS-ED data, Medicaid/CHIP enrollees younger than 18 made an estimated 628,759 asthmarelated ED visits in 2010. Using the Marketscan Medicaid database, we estimated that the average cost per visit was \$433. Given these estimates, pediatric asthma-related ED visits cost the Medicaid/CHIP programs a combined $\$ 272,453,850$ in 2010.

Seven states (California, Florida, Georgia, Illinois, New York, Pennsylvania, and Texas) are estimated to have spent more than $\$ 10$ million each in 2010 on asthma-related visits for this population (Figure, Table). California has a low prevalence of asthma (6.5\%) but the highest cost because it covers a large number of enrollees. Other states, such as New York (10.5\%) and Pennsylvania (10.9\%), have higher prevalence than states of similar size, which contribute to higher asthma costs. For perspective, if the prevalence in New York had been the same as California's, New York would have had 16,665 fewer asthma-related ED visits for this population and saved \$7.2 million in 2010.

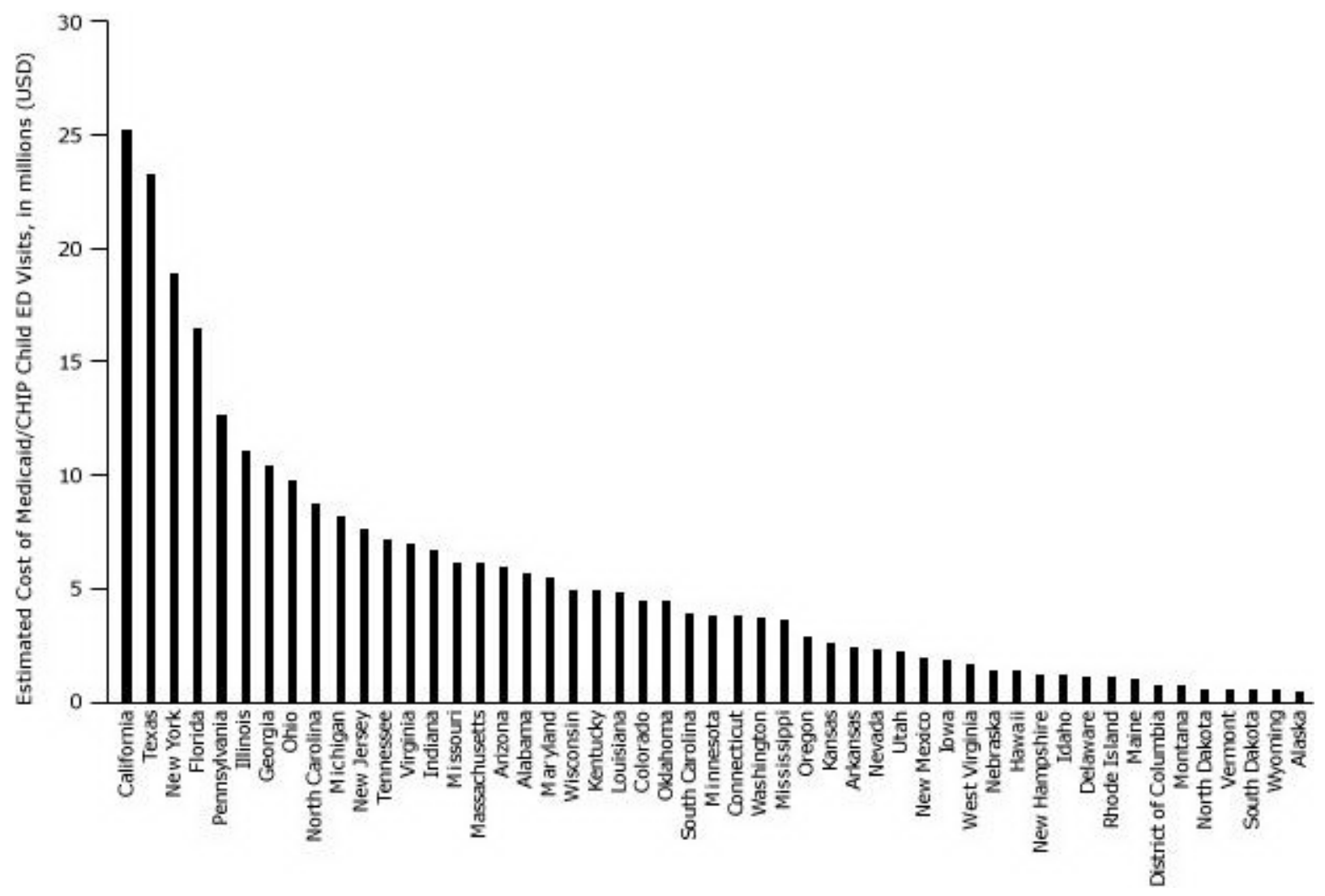

Figure. Medicaid/CHIP Spending on Asthma-Related Emergency Department Visits for Children Aged 0-17 Years, by State, 2010. Abbreviations: CHIP, Children's Health Insurance Program; ED, emergency department. [A tabular version of this figure is also available.]

We estimated that 36 states had Medicaid/CHIP costs ranging from $\$ 1$ million to $\$ 10$ million for asthma-related pediatric ED visits. Among these states, Delaware, Alabama, Tennessee, Oklahoma, Mississippi, Kentucky, Connecticut, Rhode Island, Missouri, Massachusetts, and Louisiana had asthma prevalence above 10\%. If a high- 
prevalence state such as Alabama (11.8\%) had the same prevalence as Washington State (5.6\%), Alabama could have eliminated about 6,763 ED visits for this population and saved \$2.9 million in 2010.

Seven states and the District of Columbia had estimated Medicaid/CHIP costs under $\$ 1$ million for asthma-related pediatric ED visits. Five (North Dakota, Montana, Alaska, South Dakota, and Wyoming) had low asthma prevalence $(<8 \%)$ and fewer enrollees compared with other states. In contrast, the District of Columbia had a high asthma prevalence of $15.5 \%$, and Vermont had an asthma prevalence of $8.6 \%$. If the asthma prevalence for Vermont equaled that for South Dakota, Vermont could have eliminated 398 ED visits for this population and saved \$172,602 in 2010 (Figure, Table).

\section{Discussion}

Our analysis estimated that state Medicaid programs combined spent in excess of $\$ 272$ million on pediatric asthmarelated ED visits in the United States in 2010. These results supplement data presented in the CDC Chronic Disease Calculator that provides estimates of the overall costs of asthma to states. Our data focuses specifically on pediatric ED visits, which are only a small portion of total asthma costs (15).

This research addresses a gap in the literature pertaining to Medicaid expenditures associated with pediatric asthma ED visits, costs that can be reduced through increased access to evidence-based interventions, including those provided in the home. To our knowledge, these estimates are the first of their type and could help state Medicaid directors and policy makers determine policy options for reducing costs of pediatric asthma.

Expanded coverage into nontraditional settings resulting in an uptake of preventive services could reduce asthma prevalence and asthma health disparities. Further research will better quantify whether reduced asthma-related costs result from nontraditional providers delivering services in home-based settings.

Home-based interventions can show a return on investment. The Community Preventive Services Task Force documented studies that demonstrated savings ranging from $\$ 5.30$ to $\$ 14$ for every dollar invested in home-based asthma interventions focused on children and adolescents. Community-based asthma interventions, including those provided in the home, help children proactively mitigate asthma triggers and help them manage asthma symptoms throughout their daily routines (16). A study of Boston's Community Asthma Initiative (CAI) indicated that the program involving 283 children - which included home-based asthma education and other asthma services provided by community health workers - improved health outcomes and reduced ED visits, hospital admissions, missed school days, and parent work days (17). A related analysis found that "investments in a community asthma case management program can lead to large returns from the cost savings generated by the program" and that the CAI program was paying for itself within 2 years of implementation and was demonstrating cost savings after 3 years (18).

Innovative research projects being conducted by the New England Asthma Innovations Collaborative and funded by the Centers for Medicare and Medicaid Innovation (CMMI) are focusing on service delivery and payment systems for asthma. Those projects may also contribute to the evidence base for providing and paying for services that prevent asthma. That project is novel in exploring the spectrum of asthma preventive services in various settings, which are provided by both nonclinicians and clinicians and paid for by public or private insurance plans (19). Additional innovative projects would help us understand how payment mechanisms can influence health outcomes.

Effective January 1, 2014, CMS implemented an updated regulation (42 CFR section 440.130) regarding which providers can be reimbursed for providing preventive services to Medicaid and CHIP beneficiaries. Prior to January 1, 2014, the regulation limited the coverage of preventable services to those that were actually provided by a physician or other licensed practitioner. As a result, some state Medicaid programs limited their coverage of preventive services to those furnished by licensed providers in a clinical setting. The regulation subsequently limited access to services and evidence-based interventions in homes and other community settings for Medicaid beneficiaries. In the final rule, CMS updated the regulation to allow state Medicaid programs to reimburse for preventive services provided by professionals such as community health workers or asthma educators so long as the service was initially recommended by a physician or other licensed practitioner (20). This change adds more flexibility to the Medicaid regulation that already allows states discretion over the setting in which care is provided. Thus, this final rule change on provider qualification, in combination with existing flexibility for states to define practice setting, can allow states to reimburse for asthma interventions that use nontraditional providers in a nonclinical setting.

Our estimates of asthma-related state ED visits covered by Medicaid and CHIP are subject to several limitations. One limitation is the different definition of "child" in different data sets used for our analysis. NSCH defines a child as being younger than 18 years, whereas our estimates of child enrollment in state Medicaid/CHIP programs include 18-yearolds. Provided that the proportion of 18-year-old enrollees relative to the number of total childhood enrollees is similar between states, our estimates are unbiased. If a particular state has a larger number of 18 -year-olds, the burden estimate for that state will be overestimated, and the burden estimate for other states will be underestimated. Our estimates also assume that the ED visit rate per childhood asthma enrollee is constant among states. If the ED visit 
rate is lower in a particular state, then that state's burden will be overestimated by our methods and other states' burden would be underestimated.

Another limitation is that we identified our sample of visits by including the ICD code of 493.xx in any of the 3 possible codes related to the visit. Our approach may overestimate the numbers of visits directly caused by asthma. However, asthma was listed as a contributing factor to the visit. The clinician may also use a different ICD code such as 466.19 for bronchitis before he or she actually determines the underlying cause of the condition. Therefore, these analyses would not include visits that include diagnoses that are related to asthma. These analyses focused on diagnosed asthma.

Finally, our cost estimates are based on the Marketscan Medicaid data set for 2011. This data set contains claims data for Medicaid enrollees in 11 unidentified participating states. Although the average cost for an asthma-related ED visit (and subsequent hospitalizations) is $\$ 433$ for these states, individual states may have higher or lower asthma treatment costs because Medicaid payment rates vary by state and provider type (21). According to a 2009 report by New York State, the average cost to Medicaid managed care enrollees for an asthma-related ED visit in 2007 was \$243 (22). Therefore, we believe that the estimate taken from the 2011 Marketscan data is not out of reason. Furthermore, this estimate accounts for only the actual reimbursement by Medicaid for the ED visit, which is typically lower than reimbursements by other payers as well as lower than actual costs.

This analysis provides state-based estimates of costs for pediatric ED visits and brings attention to how much states are spending for this preventable condition. The CMS rule change described in this article may help states reduce costs of asthma treatment and at the same time reduce the severity of this condition through better management. Reduced costs for treating asthma may improve the overall quality of life and productivity for children and adolescents by improving asthma symptoms and reducing the number of school days missed due to asthma. We believe that the information presented here, despite its limitations, can be useful to policy makers in assessing options for decreasing Medicaid costs of asthma.

\section{Acknowledgments}

All work was conducted by employees of CDC and no outside funding was received for this work.

\section{Author Information}

Corresponding Author: William S. Pearson, PhD, Office of the Associate Director for Policy, Centers for Disease Control and Prevention, 1600 Clifton Rd NE, Mailstop E-02, Atlanta, GA 30329. Telephone: 404-639-6459. E-mail: Wpearson@cdc.gov.

Author Affiliations: Scott A. Goates, Samantha D. Harrykissoon, Scott A. Miller, Centers for Disease Control and Prevention, Atlanta, Georgia.

\section{References}

1. National Heart Lung and Blood Institute, National Institutes of Health. Expert Panel Report 3: guidelines for the diagnosis and management of asthma. National Asthma Education and Prevention Program. NIH publication no. 07-4051. https://www.nhlbi.nih.gov/guidelines/asthma/gip_rpt.pdf. Accessed November 17, 2013.

2. Akinbami LJ, Moorman JE, Bailey C, Zaharan HS, King M, Johnson CA, et al. Trends in asthma prevalence, health care use, and mortality in the United States, 2001-2010. NCHS data brief 2012;(94):1-8. PubMed 圈

3. Barnett SB, Nurmagambetov TA. Costs of asthma in the United States: 2002-2007. J Allergy Clin Immunol 2011;127(1):145-52. CrossRef 圈 PubMed 圈

4. Centers for Disease Control and Prevention. Asthma's impact on the nation. http://www.cdc.gov/asthma/impacts_nation/asthmafactsheet.pdf. Accessed September 30, 2013.

5. Centers for Disease Control and Prevention. National Center for Health Statistics, National Hospital Discharge Survey, 1995-2010. Analysis by the American Lung Association Research and Health Education Division using SPSS software. http://www.lung.org/lung-disease/asthma/resources/facts-and-figures/asthma-children-factsheet.html\# 4. Accessed November 5, 2013.

6. Finkelstein JA, Barton MB, Donahue JG, Algatt-Bergstrom P, Markson LE, Platt R. Comparing asthma care for Medicaid and non-Medicaid children in a health maintenance organization. Arch Pediatr Adolesc Med 2000;154 (6):563-8. CrossRef 圈 PubMed 圈 
7. Centers for Disease Control and Prevention. Vital signs: asthma prevalence, disease characteristics, and selfmanagement education: United States, 2001-2009. MMWR Morb Mortal Wkly Rep 2011;60(17):547-62. PubMed 圈

8. Clark N, LaChance L, Milanovich A, Stoll S, Awad DF. Characteristics of successful asthma programs. Public Health Rep 2009;124(6):797-805. PubMed 国

9. Brown AS, Disler S, Burns L, Carlson A, Davis A, Kurian C, et al. Family and home asthma services across the Controlling Asthma in American Cities Project. J Urban Health 2011;88(Suppl 1):100-12. CrossRef 国 PubMed 圈

10. The Community Guide for Preventive Services. Asthma: home-based, multi-trigger, multicomponent environmental interventions. http://www.thecommunityguide.org/asthma/multicomponent.html. Accessed September 30, 2013.

11. Centers for Disease Control and Prevention. NAMCS/NHAMCS - about the Ambulatory Health Care Surveys. http://www.cdc.gov/nchs/ahcd.htm. Accessed August 15, 2013.

12. National Survey of Children's Health: Data Resource Center for Child and Adolescent Health. http://www.childhealthdata.org/learn/NSCH. Accessed September 20, 2013.

13. Kaiser Family Foundation - Health Policy Research. Analysis, polling, facts, data and journalism. State category, Medicaid and CHIP, The Henry J. Kaiser Family Foundation. http://kff.org/other/state-indicator/trends-inmonthly-chip-enrollment-june/ and http://kff.org/medicaid/state-indicator/distribution-by-enrollment-group/. Accessed September 20, 2013.

14. Truven Health Analytics. Marketscan Research Databases. http://truvenhealth.com/Portals/o/assets/ACRS_11223_0912_MarketScanResearch_SS_Web.pdf. Accessed August 1, 2013.

15. Centers for Disease Control and Prevention and RTI International. Chronic disease cost calculator version 2. http://www.cdc.gov/chronicdisease/resources/calculator/. Accessed December 5, 2013.

16. Nurmagambetov TA, Barnett SBL, Jacob V, Chattopadhyay SK, Hopkins DP, Crocker DD, et al. Economic value of home-based, multi-trigger, multicomponent interventions with an environmental focus for reducing asthma morbidity: a Community Guide systematic review. Am J Prev Med 2011;41(2S1):S33-S47. PubMed 圈

17. Woods ER, Bhaumik U, Sommer SJ, Ziniel SI, Kessler AJ, Chan E, et al. Community asthma initiative: evaluation of a quality improvement program for comprehensive asthma care. Pediatrics 2012;129(3):465-72. CrossRef 圈 PubMed 圈

18. Bhaumik U, Norris K, Charron G, Walker SP, Sommer SJ, Chan E, et al. A cost analysis for a community-based case management intervention program for pediatric asthma. J Asthma 2013;50(3):310-7. CrossRef 圈 PubMed 国

19. Center for Medicare \& Medicaid Innovation. Health Care Innovation Awards: project profiles. http://innovation.cms.gov/initiatives/participant/Health-Care-Innovation-Awards/Health-Resources-InAction.html. Accessed December 1, 2013.

20. Diagnostic, Screening, Preventive, and Rehabilitative Services, Final Rule. Fed Regist 2013;78:42226-8. http://www.law.cornell.edu/cfr/text/42/440.130. Accessed April 17, 2014.

21. Medicaid: use of claims data for analysis of provider payment rates. Washington (DC): United States Government Accountability Office; 2014. http://www.gao.gov/products/GAO-14-56R. Accessed April 17, 2014.

22. New York State Asthma Surveillance Summary Report. New York (NY): New York State Department of Health; 2009. http://www.health.ny.gov/statistics/ny_asthma/pdf/2009_asthma_surveillance_summary_report.pdf. Accessed March 4, 2014.

\section{Table}

Table. Estimates of Asthma Prevalence, Medicaid/Children's Health Insurance Program (CHIP) Enrollment, and Asthma-Related Pediatric Emergency Department (ED) Visits by State for US Children Aged o-17 Years, 2010

\begin{tabular}{|c|c|c|c|c|c|}
\hline & $\begin{array}{c}\text { Estimated } \\
\text { Asthma } \\
\text { Prevalence } \\
\text { Among } \\
\text { Children, \% }\end{array}$ & $\begin{array}{c}\text { Estimated No. of } \\
\text { Children Covered } \\
\text { by Medicaid/CHIP }\end{array}$ & $\begin{array}{c}\text { Estimated No. of } \\
\text { Medicaid/CHIP- } \\
\text { Covered Children } \\
\text { with Asthmaa }\end{array}$ & $\begin{array}{c}\text { Estimated No. of } \\
\text { Asthma-Related ED } \\
\text { Visits Covered by } \\
\text { Medicaid/CHIP }\end{array}$ & $\begin{array}{c}\text { Estimated Cost of } \\
\text { Medicaid/CHIP } \\
\text { Child ED Visits (\$) }\end{array}$ \\
\hline
\end{tabular}


Preventing Chronic Disease | State-Based Medicaid Costs for Pediatric Asthma Emergenc... Page 7 of 8

\begin{tabular}{|c|c|c|c|c|c|}
\hline State & $\begin{array}{c}\text { Estimated } \\
\text { Asthma } \\
\text { Prevalence } \\
\text { Among } \\
\text { Children, \% }\end{array}$ & $\begin{array}{l}\text { Estimated No. of } \\
\text { Children Covered } \\
\text { by Medicaid/CHIP }\end{array}$ & $\begin{array}{l}\text { Estimated No. of } \\
\text { Medicaid/CHIP- } \\
\text { Covered Children } \\
\text { with Asthmaa }\end{array}$ & $\begin{array}{l}\text { Estimated No. of } \\
\text { Asthma-Related ED } \\
\text { Visits Covered by } \\
\text { Medicaid/CHIP }\end{array}$ & $\begin{array}{l}\text { Estimated Cost of } \\
\text { Medicaid/CHIP } \\
\text { Child ED Visits (\$) } \\
\text { b }\end{array}$ \\
\hline Total & 8.8 & $37,615,535$ & $3,313,869$ & 628,759 & $272,454,000$ \\
\hline AK & 3.6 & 85,003 & 3,060 & 650 & 282,000 \\
\hline$A L$ & 11.8 & 585,768 & 69,121 & 12,873 & $5,578,000$ \\
\hline AR & 8.0 & 455,683 & 36,455 & 5,483 & $2,376,000$ \\
\hline$A Z$ & 8.7 & 720,427 & 62,677 & 13,652 & $5,916,000$ \\
\hline CA & 6.5 & $5,614,747$ & 364,959 & 58,200 & $25,219,000$ \\
\hline $\mathrm{CO}$ & 8.7 & 444,142 & 38,640 & 10,271 & $4,451,000$ \\
\hline CT & 11.0 & 330,310 & 36,334 & 8,657 & $3,751,000$ \\
\hline DC & 15.5 & 88,179 & 13,667 & 1,505 & 652,000 \\
\hline DE & 12.0 & 98,380 & 11,805 & 2,379 & $1,031,000$ \\
\hline $\mathrm{FL}$ & 9.9 & $2,151,703$ & 213,019 & 38,166 & $16,538,000$ \\
\hline GA & 10.0 & $1,321,941$ & 132,194 & 24,001 & $10,400,000$ \\
\hline $\mathrm{HI}$ & 9.9 & 137,057 & 13,569 & 2,897 & $1,256,00 c$ \\
\hline IA & 5.8 & 315,976 & 18,326 & 4,067 & $1,762,000$ \\
\hline ID & 6.1 & 166,424 & 10,152 & 2,521 & $1,093,000$ \\
\hline IL & 8.5 & $1,738,547$ & 147,776 & 25,622 & $11,102,000$ \\
\hline IN & 9.9 & 765,624 & 75,797 & 15,338 & $6,646,000$ \\
\hline KS & 8.3 & 264,408 & 21,946 & 5,812 & $2,519,000$ \\
\hline $\mathrm{KY}$ & 11.2 & 507,771 & 56,870 & 11,041 & $4,784,000$ \\
\hline LA & 10.1 & 765,634 & 77,329 & 10,877 & $4,713,000$ \\
\hline MA & 10.2 & 635,442 & 64,815 & 13,942 & $6,041,000$ \\
\hline MD & 9.6 & 574,712 & 55,172 & 12,512 & $5,422,000$ \\
\hline ME & 8.2 & 141,526 & 11,605 & 2,169 & 940,000 \\
\hline MI & 8.4 & $1,219,772$ & 102,461 & 18,967 & $8,219,000$ \\
\hline MN & 7.1 & 451,077 & 32,026 & 8,782 & $3,806,000$ \\
\hline MO & 10.2 & 654,024 & 66,710 & 14,006 & $6,069,000$ \\
\hline MS & 11.4 & 469,395 & 53,511 & 8,297 & $3,595,000$ \\
\hline MT & 6.4 & 96,432 & 6,172 & 1,378 & 597,000 \\
\hline NC & 9.2 & $1,132,557$ & 104,195 & 20,221 & $8,762,000$ \\
\hline ND & 7.6 & 48,808 & 3,709 & 1,097 & 475,000 \\
\hline NE & 6.8 & 188,248 & 12,801 & 3,008 & $1,303,000$ \\
\hline $\mathrm{NH}$ & 9.3 & 107,748 & 10,021 & 2,573 & $1,115,000$ \\
\hline NJ & 8.8 & 742,003 & 65,296 & 17,507 & $7,586,000$ \\
\hline NM & 8.7 & 358,242 & 31,167 & 4,347 & $1,884,000$ \\
\hline NV & 8.0 & 224,013 & 17,921 & 5,125 & $2,221,000$ \\
\hline NY & 10.5 & $2,489,543$ & 261,402 & 43,745 & $18,956,000$ \\
\hline $\mathrm{OH}$ & 8.5 & $1,335,574$ & 113,524 & 22,359 & $9,689,00 c$ \\
\hline
\end{tabular}




\begin{tabular}{|c|c|c|c|c|c|}
\hline State & $\begin{array}{c}\text { Estimated } \\
\text { Asthma } \\
\text { Prevalence } \\
\text { Among } \\
\text { Children, \% }\end{array}$ & $\begin{array}{l}\text { Estimated No. of } \\
\text { Children Covered } \\
\text { by Medicaid/CHIP }\end{array}$ & $\begin{array}{l}\text { Estimated No. of } \\
\text { Medicaid/CHIP- } \\
\text { Covered Children } \\
\text { with Asthmaa }\end{array}$ & $\begin{array}{l}\text { Estimated No. of } \\
\text { Asthma-Related ED } \\
\text { Visits Covered by } \\
\text { Medicaid/CHIP }\end{array}$ & $\begin{array}{c}\text { Estimated Cost of } \\
\text { Medicaid/CHIP } \\
\text { Child ED Visits (\$) } \\
\text { b }\end{array}$ \\
\hline OK & 11.4 & 559,482 & 63,781 & 10,209 & $4,424,000$ \\
\hline OR & 7.7 & 380,566 & 29,304 & 6,427 & $2,785,000$ \\
\hline PA & 10.9 & $1,274,545$ & 138,925 & 29,317 & $12,704,000$ \\
\hline RI & 10.9 & 112,099 & 12,219 & 2,352 & $1,019,000$ \\
\hline SC & 8.5 & 540,188 & 45,916 & 8,847 & $3,834,000$ \\
\hline SD & 5.4 & 92,841 & 5,013 & 1,055 & 457,000 \\
\hline TN & 11.5 & 860,553 & 98,964 & 16,573 & $7,181,000$ \\
\hline TX & 8.1 & $3,699,623$ & 299,669 & 53,572 & $23,214,000$ \\
\hline UT & 5.8 & 246,406 & 14,292 & 4,867 & $2,109,000$ \\
\hline VA & 9.0 & 671,413 & 60,427 & 16,071 & $6,964,000$ \\
\hline VT & 8.6 & 72,805 & 6,261 & 1,071 & 464,000 \\
\hline WA & 5.6 & 796,010 & 44,577 & 8,531 & $3,696,000$ \\
\hline WI & 8.7 & 596,145 & 51,865 & 11,226 & $4,864,000$ \\
\hline WV & 9.9 & 223,847 & 22,161 & 3,695 & $1,601,000$ \\
\hline WY & 6.9 & 62,172 & 4,290 & 900 & 390,000 \\
\hline
\end{tabular}

a Childhood asthma prevalence is the weighted average of each state's asthma prevalence total weighted by the number of covered children in the state and is not a nationally representative prevalence estimate.

b These estimates have been rounded to the nearest $\$ 1,000$.

The opinions expressed by authors contributing to this journal do not necessarily reflect the opinions of the U.S. Department of Health and Human Services, the Public Health Service, the Centers for Disease Control and Prevention, or the authors' affiliated institutions.

For Questions About This Article Contact pcdeditor@cdc.gov

Page last reviewed: June 26, 2014

Page last updated: June 26, 2014

Content source: National Center for Chronic Disease Prevention and Health Promotion

Centers for Disease Control and Prevention 1600 Clifton Rd. Atlanta, GA 30333, USA

800-CDC-INFO (800-232-4636) TTY: (888) 232-6348 - Contact CDC-INFO

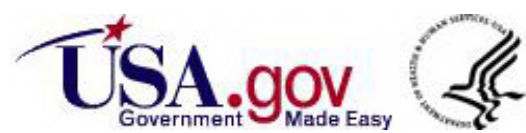

